\title{
periferio
}

\section{EDUCAÇÃO BILÍNGUE DE SURDOS E A POSSÍVEL CONTRIBUIÇÃO DA FORMAÇÃO EM PEDAGOGIA: DESAFIOS ATUAIS}

\author{
Bianca Salles Conceição ${ }^{1}$ \\ Universidade Federal de São Carlos - UFSCar \\ Vanessa Regina de Oliveira Martins ${ }^{2}$ \\ Universidade Federal de São Carlos - UFSCar
}

\section{Resumo}

Este artigo tem como objetivo trazer um recorte dos estudos empreendidos no trabalho de conclusão de curso de pedagogia na Universidade Federal de São Carlos (UFSCar). Problematizou-se a formação de pedagogos no que concerne a proposta curricular oferecida nas Universidades Federais do Estado de São Paulo. $O$ intuito foi o de verificar se a proposta formativa atual visa atender a demanda legal do Decreto 5.626/05 em relação à formação de professores bilíngues nos anos iniciais. Analisou-se se a proposta curricular direciona a reflexão do ensino e da aprendizagem de pedagogos para uma atuação em salas língua de instrução Libras. Trata-se de uma pesquisa de abordagem qualitativa, com investigação do tipo descritiva de cunho documental. Sobre a pesquisa documental, os dados foram coletados a partir das grades e ementas das Universidades Federais do Estado de São Paulo dos cursos de Licenciatura em Pedagogia nas disciplinas relacionadas à Língua Brasileira de Sinais, balizados pelo Decreto 5.626/05 e a Política Nacional de Educação Especial (PNEE). Com os resultados observa-se que os cursos de formação de professores dos anos iniciais mantêm a lógica da educação inclusiva. As representações da surdez enquanto deficiência e da língua de sinais como instrumento emanam políticas formativas: como carga-horária mínima para a disciplina de Libras, nenhum direcionamento para a alfabetização de crianças surdas. Tal perspectiva fomenta a proposta de educação de surdos baseada pelo atendimento educacional especializado (AEE) e não pela lógica de salas bilíngues, Libras/ Língua Portuguesa.

Palavras chave: surdez; pedagogia bilíngue; inclusão escolar

\footnotetext{
${ }^{1}$ Graduanda do curso de pedagogia da Universidade Federal de São Carlos (UFSCar) e aluna do Programa de Pós-graduação do Mestrado em Educação Especial (PPGEEs).

2 Doutora em Educação. Professora e pesquisadora do curso de bacharelado em tradução e interpretação em Libras/ Língua Portuguesa na Universidade Federal de São Carlos (UFSCar)
} 


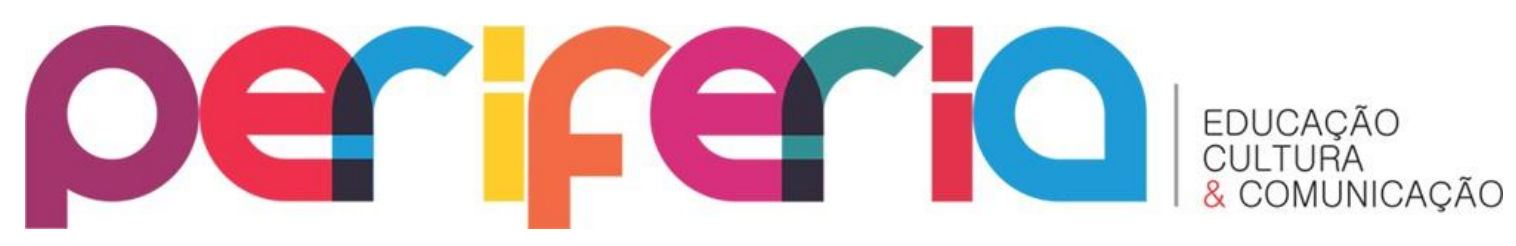

\title{
BILINGUAL EDUCATION OF DEAFTS AND POSSIBLE CONTRIBUTION OF TRAINING IN PEDAGOGY: CURRENT CHALLENGES
}

\begin{abstract}
The object of this research is to problamatize the pedagogue formation, checking if the curriculum proposal ofered in the Federal Universities of São Paulo State is accord to the legal demand of Decree 5.626/05 in relation with the pedagogue bilingal formation in the early years. The focus is to realize if the proposed curriculum directs for teaching and learning reflection with sign language, according to the composition about Libras instrution language classes. This research is about a completion of course work, by having qualitative approach, with documentary descriptive research. The bibliographic references to this search were withdrawals of databases like on line repositories of CAPES dissertations ans theses - BDTD, Scientific Eletronic Library Online (SciELO) and CAPES research groups. The bibliography was related with deaf educatiom. It was realized a documental research. The databeses were colected in Universities Federal of São Paulos's menus of the Libras subject pedagogy courses based on Decreet 5.626/05 and the National Policy on Spetial Education. Can observe with the results, that teachers of the early years courses's formation keeps the inclusive education logic. The deafness representations while deficiency and the sign language as na instrument proceed formative politics, like minimum workload of Libras subject. Such perspective encourages the deaf education proposal based by a skills attendance education and not for the bilingal (Libras/ Portuguese Languase) classes logic.
\end{abstract}

Keywords: deafness; bilingal pedagogy; school inclusion. 


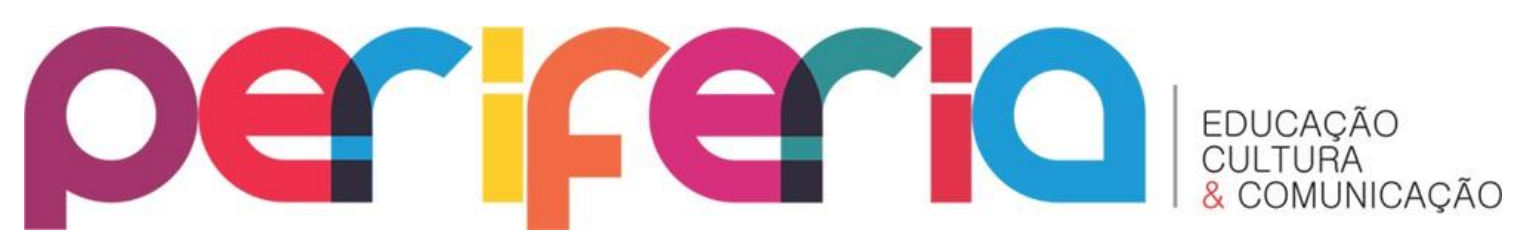

\section{INTRODUÇÃOO}

Esse artigo objetiva trazer um recorte das análises realizadas com o término da pesquisa empreendida como requisito para a conclusão do curso de pedagogia na Universidade Federal de São Carlos (UFSCar). 0 trabalho objetivou problematizar a formação de pedagogos na atualidade, verificando se a proposta curricular oferecida nas universidades federais do Estado de São Paulo visa atender a demanda legal, a partir do Decreto 5.626/05 (BRASIL, 2005), em relação à pedagogia bilíngue, direcionando uma formação que priorize o ensino de surdos pela língua de sinais; ou seja, pretendeu-se refletir, de modo geral, se a perspectiva de educação de surdos tem sido difundida socialmente e de que modo tem adentrado no espaço escolar.

Faremos inicialmente um movimento teórico de historicização da educação de surdos e os dilemas atuais em relação à política de educação inclusiva a qual, muitas vezes, contradiz a perspectiva trazida pelos movimentos surdos e o Decreto 5.626/05 (BRASIL, 2005) - norteador para a proposta bilíngue educacional. Em relação ao procedimento metodológico de investigação, apontamos esse trabalho como uma pesquisa qualitativa descritiva de cunho documental. Os documentos analisados foram: o Decreto 5.626/05 (BRASIL, 2005) e a Política Nacional de Educação Especial na Perspectiva Inclusiva (PNEE) (BRASIL, 2008). Para analisar o modo de formação oferecido nos cursos de pedagogia e o possível alinhamento a uma perspectiva bilíngue rastreou-se, por meio de ferramentas online aos sites, as grades juntamente com as ementas curriculares dos cursos de Licenciatura em Pedagogia em Universidades Federais do Estado de São Paulo. Desse recorte, tivemos acesso a apenas três Universidades Federais do Estado de São Paulo. Todavia, para esse trabalho, por conta de espaço de discussão, traremos os resultados do estudo de apenas uma das universidades a qual reflete resultados comuns encontrados nas demais.

Com a coleta e mais a pesquisa bibliográfica pudemos trazer algumas considerações sobre o momento político atual de formação de pedagogos e as 


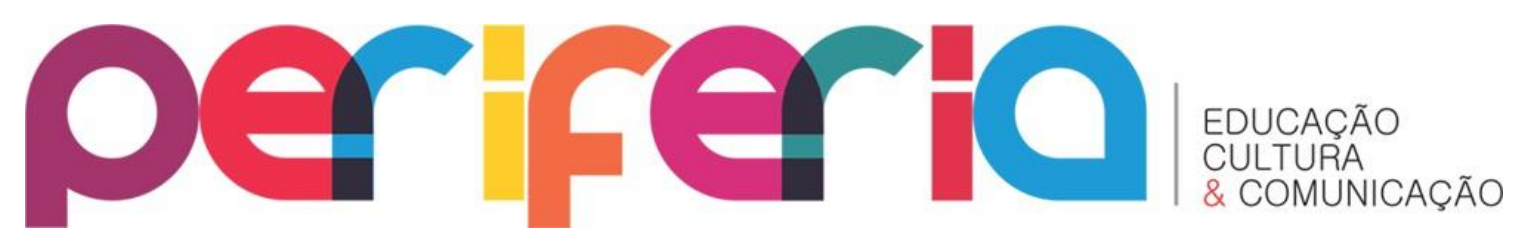

perspectivas ideológicas que mantém a lógica formativa, de modo geral, no Estado de São Paulo. Sugere-se que a prática escolar está alinhada ao modelo da educação especial com a lógica de entrada da língua de sinais apenas no contraturno. Deriva-se isso ao observar o pouco direcionamento à aprendizagem da língua de sinais no currículo dos futuros pedagogos, bem como a ausência de disciplinas que direcionem a alfabetização e o letramento de alunos que não terão o português como primeira língua. A instrução escolar é baseada na língua portuguesa e não na língua de sinais. Tais agenciamentos refletem em modelos de escola e constituição de subjetividades surdas, a saber, movidas pelo apagamento de suas diferenças, ao enquadrá-las na lógica do ensino para ouvintes. Portanto, ao analisar as matrizes curriculares dos cursos de Licenciatura em Pedagogia das Universidades Federais do Estado de São Paulo, relacionando com a proposta de formação desse profissional, com base no que é proposto no Decreto 5.626/05 (BRASIL, 2005), encontramos algumas carências, ou melhor, uma ligação na perspectiva de enunciação da surdez pela lógica da deficiência, e da Libras como apoio, ou instrumento de ensino.

\section{EDUCAÇÃO BILÍNGUE DE SURDOS: PERCURSOS HISTÓRICOS E A ATUALIDADE}

Iniciaremos trazendo uma revisão da história da educação de surdos e as lutas travadas na atualidade, as quais produzem inúmeras práticas enviesadas por diversas concepções sobre o surdo, a surdez, a linguagem e sua língua. Tais concepções efetivam formas de conceber a relação corporal do surdo e os modos de produção de políticas educacionais: o que seja pensar as práticas de uso da língua de sinais, ou não, na educação de surdos. Pode-se afirmar que tais disputas sobre o modo de fazer educação de surdos teve inicio há séculos, ora sendo atestada a humanidade para o sujeito surdo por meio do aprendizado da fala, ora dentro de discursos religiosos, e em outros aspectos no seio de produções discursivas assistenciais. A educação de surdos 


\section{periferio}

teve seu ponto de partida na esfera religiosa e hoje ganha espaço de luta de inserção nas salas de aulas numa lógica não assistencial, mas de direito, baseada no discurso da diferença linguística. Todavia, nota-se que os surdos foram marginalizados dos processos escolares pela diferença linguística (SOARES, 1999; LACERDA, 1998; GESSER, 2009; LACERDA; SANTOS; MARTINS, 2016; MARTINS, 2008a). As mudanças na história estão marcadas por diversos conflitos e só assim os surdos puderam conquistar direitos de acessibilidade linguística, como, por exemplo, o reconhecimento da língua de sinais e seu regulamento por vias legais. (BRASIL, 2005).

É importante salientar que os surdos foram, por séculos, privados de utilizar a língua de sinais. O diálogo sinalizado já foi proibido e até mesmo marginalizado, forçando os mesmos à oralização, ou seja, um método baseado exclusivamente pelo ensino da oralidade, onde esses sujeitos se viam narrados pela falta orgânica, ou seja, como deficientes auditivos (SOARES, 1999). Tal perspectiva conduziu práticas de ensino voltadas ao direcionamento oral em detrimento dos conteúdos escolares: a escola tornou-se clínica da linguagem.

Segundo Gesser (2009), existem relatos de que dentro dos ambientes escolares, se algum surdo fizesse o uso da língua de sinais, teriam suas mãos amarradas e sofreriam vários tipos de castigos físicos. Além disso, a visão aristotélica durante toda a antiguidade considerava os surdos seres não educáveis, seguindo a ideia de que a fala se vincula ao pensamento, portanto, se uma pessoa não fizesse uso da fala oral, logo ela estaria privada do pensamento. (LACERDA, 1998). A escola se torna impregnada da concepção oral como modelo educacional, valorizando o uso de técnicas que visassem a oralidade, já que nessa premissa o sujeito só se constitui humano se desenvolver a língua oral - outros fatores são deixados de lado.

Uma das premissas com que inicialmente dizia respeito à predominância do procedimento clínico na educação de surdos, e que, possivelmente teria feito com que a escolaridade fosse colocada em segundo plano, isto é, ao conteúdo escolar não era dada a mesma importância que se 


\section{periferio}

dava aos exercícios específicos, considerados para adquirir a linguagem oral (SOARES, 1999, p. 24).

Gesser (2009), afirma que em algumas narrativas históricas conta-se que a sinalização era vista como algo exótico, obsceno e extremamente agressivo, já que o surdo expunha demais o corpo para sinalizar. Tais embates para a entrada da língua de sinais na escola e na vida do surdo foram travados por longos períodos.

Assim, com a continuidade do uso da língua de sinais, em ambiente escondidos, e a luta cravada pelos surdos anos a fio, dividindo tanto o quesito social como cultural, a língua de sinais foi ganhando espaço cada vez maior. A língua de sinais assegura um sentimento de valorização da diferença e ganho de uma identidade surda. Juntamente a esse movimento de valorização da língua, os movimentos surdos partilhavam de tensões no que se diz respeito à escolarização dos surdos. No entanto, conforme apontado, a educação filiouse por muito tempo a construção de práticas normalizadoras, relacionadas ao ensino da língua oral.

No século XVIII as práticas gesticulares começaram a ganhar força, sendo disseminadas pela Europa, que se baseava na aprendizagem dos sinais através da interação com os surdos para então ensiná-los leitura, escrita e fala (SOARES, 1999). Em obras históricas é possível ter acesso mais as práticas gestualistas que as oralistas, nesses períodos citados, pois seus autores faziam questão da divulgação do método pedagógico investido. Ressalta-se que Abade L'Epée foi um dos precursores desse movimento, inventando a partir do contato com surdos adultos o uso dos sinais metódicos para a alfabetização de surdos (SOARES, 1999). No entanto, há um travamento do uso de gestos na educação de surdos após o II Congresso Internacional de Milão, em 1880. Nele o voto pela continuidade do uso da oralidade foi maior, sendo estabelecido o método oral puro, ou seja, os surdos poderiam usar somente a leitura labial e a fala, sendo banida a presença da gestualidade implantada por L'Epèe e seus seguidores (SOARES, 1999). 


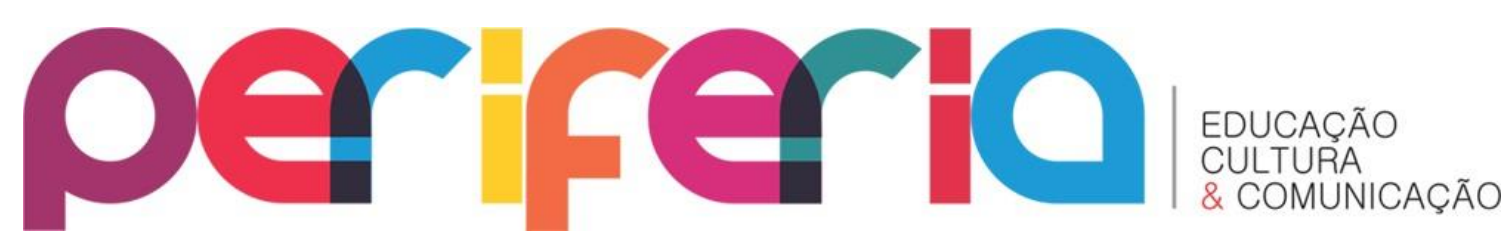

Com a proibição do uso de sinais na educação de surdos, perspectivas educacionais foram sendo incorporadas. Foi necessário um movimento intenso entre os surdos e defensores de propostas educacionais que priorizassem a língua de sinais para uma ruptura conceitual e para a entrada de novas práticas. Tivemos pelo menos três abordagens educacionais na educação de surdos, sendo elas: o oralismo, a comunicação total e o bilinguismo. As duas primeiras priorizavam o ensino baseado na abordagem oral. A diferença para a comunicação total é que, embora o foco voltava-se para o ensino da língua oral, permitiam-se usos de outros recursos, inclusive de gestos para esse fim. Para chegarmos a abordagem educacional bilíngue, que consiste no ensino baseado pela língua de sinais como primeira língua (L1) e a língua majoritária como segunda (L2), na modalidade escrita, e que vem ganhando espaço atualmente, foi preciso muitos embates políticos. Houve todo um movimento de pesquisa e de militância para a quebra de paradigmas criados sobre as línguas de sinais. Com o trabalho de Stoke em 1960 nos Estados Unidos, comprovou-se que a língua de sinais americana (ASL) tinha em si todos os aspectos gramaticais de uma língua, e sua disseminação, por exemplo, no Brasil, implicou em grandes revoluções - não sem tensões - para que a história educacional pudesse ser narrada de outro modo, pela língua de sinais (LACERDA, 1998).

No entanto, com todas as pesquisas, inclusive argumentos de que a língua de sinais ensinada desde cedo para crianças surdas facilita seu processo de desenvolvimento cognitivo (LODI; ALBUQUERQUE, 2016), as práticas oralistas, valorizando unicamente a língua oral, mantém-se ativa ainda nos dias atuais, transvestidas em ações inclusivas - modelo de ensino proposto em muitas escolas que se dizem inclusivas - mas excluem o uso da língua de sinais na medida em que não oferecem suportes para sua presença. Portanto, os processos de exclusões linguísticas se fazem presentes na atualidade, na medida em que a escola não prioriza, ou não oferece centralidade na língua de sinais. Tais aspectos serão trabalhados nesse artigo ao analisar que tipo de formação tem sido oferecida para futuros pedagogos e qual o lugar da Libras 


\section{periferio}

(Língua Brasileira de Sinais) no currículo formativo. Com certeza tais propostas revelam posições teóricas sobre a surdez e direcionam uma prática escolar mantida.

\subsection{ESCOLA-POLO: REPENSANDO A PROPOSTA EDUCACIONAL BILÍNGUE DE SURDOS NA REDE MUNICIPAL}

Para dar continuidade a essa discussão é necessário apresentarmos a proposta de escola-polo ${ }^{3}$ como espaço de construção da cidadania surda e de uma educação bilíngue voltada às diferenças. Um modelo possível, porém que requer adequações micro (no cotidiano) e macro (nas políticas públicas). Micro no interior das escolas e macro, desde a formação até a consolidação de propostas e políticas educacionais. Essa proposta apresentada refere-se a resultados de pesquisas implantadas em escolas municipais que aderiram à perspectiva bilíngue, contra a lógica da inclusão radical, a qual o movimento surdo tanto questiona. Ou seja, trata-se de uma construção diferenciada da perspectiva inclusiva, até então proposta, e que valoriza a entrada do surdo e da língua de sinais. Para isso algumas alterações foram necessárias, desde a revisão curricular da escola à estrutura de salas de aula (LACERDA; SANTOS; MARTINS, 2016). As escolas-polo são escolas regulares ou escolas comuns da rede pública de ensino, da Educação Infantil, do Ensino Fundamental I e II e EJA. São escolas que fazem a inclusão escolar com os alunos surdos, porém oferecendo funcionários especializados para esse atendimento e outra estrutura de funcionamento na qual a Libras se coloca como língua de instrução e não instrumento de apoio escolar.

No entanto tal proposta ocorre apenas em alguns municípios como projeto e não serviço, mas na atual Política Nacional de Educação do nosso país, mais que fazer a matrícula do estudante surdo, as escolas devem

\footnotetext{
3 Proposta apresentada em projetos de pesquisa. Nessa pesquisa analisamos resultados de pesquisa ofertados no Estado de São Paulo, em escolas públicas da rede municipal. Para um aprofundamento melhor verificar os estudos na Obra "Escola e Diferença: caminhos para educação bilíngue de surdos". As referências encontram-se no texto.
} 


\section{periferio}

obrigatoriamente promover o desenvolvimento do aluno por meio da língua de sinais. Perspectiva não comum nas discussões sobre a educação inclusiva, na medida em que as práticas escolares vêm sendo construídas baseadas apenas na presença de surdos na escola, sem alterações linguísticas na instrução, e nenhuma adequação às propostas curriculares, às quais se voltam ao modelo de ensino ofertado para a maioria ouvinte. Quando muito com apoio de intérpretes educacionais, sem grandes alterações na proposta geral da escola. No entanto, os surdos tem reivindicado espaço de instrução pela Libras gerando a necessidade de revisão do espaço escolar.

As escolas-polos nascem nesse contexto, a partir do Decreto 5.626/05 (BRASIL, 2005), como projetos de pesquisas oferecidos por pesquisadores que defendem a língua de sinais como primeira língua no ensino para surdos e visam à construção de uma escola que de fato atenda as especificidades das pessoas surdas. Um modo de perversão da atual forma de inclusão de surdos proposta até o momento, na medida em que busca dentro da escola comum inclusiva atender às demandas de surdos, colocando-os como protagonistas do processo e não coadjuvante atrelado a um modelo normalizador. São denominadas escolas-polo aquelas que congregam um número significativo de estudantes surdos para a troca linguística e o fortalecimento identitário; e ainda que atenda uma proposta educacional bilíngue, baseado primeiramente no aprendizado da Libras e posteriormente na Língua Portuguesa (LP) em sua modalidade escrita. Destacamos a importância da presença de surdos adultos educadores que pensam e colaboram em sua construção. Alerta-se que a manutenção desse modelo de escola não é fácil. Isso pelas repressões contrárias advindas pelos discursos mobilizadores da inclusão radical.

Para tal, defendesse a inclusão de todos os alunos na rede regular de ensino, incluindo aqueles considerados com necessidades educacionais especiais, cabendo às escolas organizarem-se para o atendimento, assegurando as condições necessárias para uma educação de qualidade para todos. No que tange aos alunos surdos, a política educacional deve dialogar ainda com outros dois documentos oficiais que 


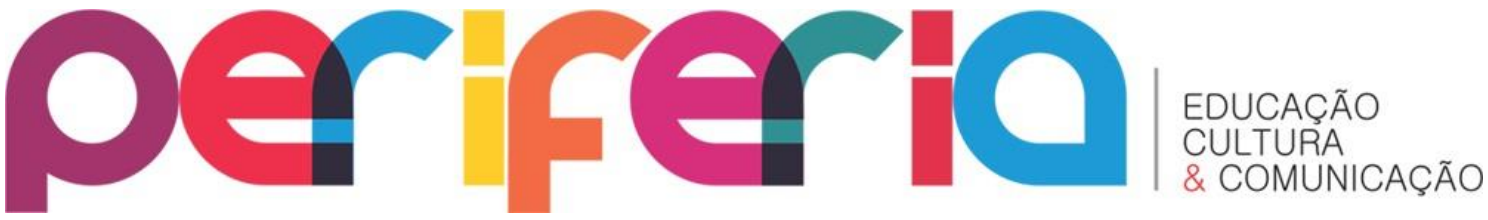

garantem como direito das pessoas surdas o reconhecimento da Língua Brasileira de Sinais (Libras) com meio legal de expressão e comunicação e, como decorrência, o desenvolvimento de práticas de ensino nos espaços escolares que garantam a educação bilíngue. (LACERDA; SANTOS; LODI; GURGEL, 2016, p. 13)

Sobre a estrutura do projeto apresentado, a escola contava com docentes bilíngues nos anos iniciais, ou educação infantil e ensino fundamental I, docentes bilíngues de ensino de português com segunda língua nos anos finais ou ensino fundamental II, intérpretes de língua de sinais e instrutores surdos. Os profissionais dessa rede receberam formação em serviço e acompanhamento para a contínua melhoria da escola. Os alunos ouvintes recebiam aulas de Libras. Para os anos iniciais ofertava-se a presença de salas de aulas para alunos surdos, sendo nomeadas "salas língua de instrução Libras". Tais espaços contavam com a presença de professores bilíngues ouvintes e instrutores surdos, trabalhando em parceria. Não teremos como desdobrar a especificidade de cada profissional nesse projeto, todavia, o intuito foi o de marcar a existência de propostas educacionais inclusivas que destoam da prática comum de inserção de surdos sem alterações no espaço e currículo escolar. Para esse trabalho adensaremos apenas um tópico do projeto: as salas língua de instrução Libras, com a presença de professores bilíngues. Essa temática é relevante, pois na defesa de sua existência, há que pensar a promoção de formação de pedagogos que atendam esses espaços de ensino na educação infantil e no ensino fundamental I. Considerando que nos anos iniciais não é adequado o ensino mediado pela atuação de intérpretes educacionais e sim por meio de professores bilíngues em salas com instrução pela Libras. 


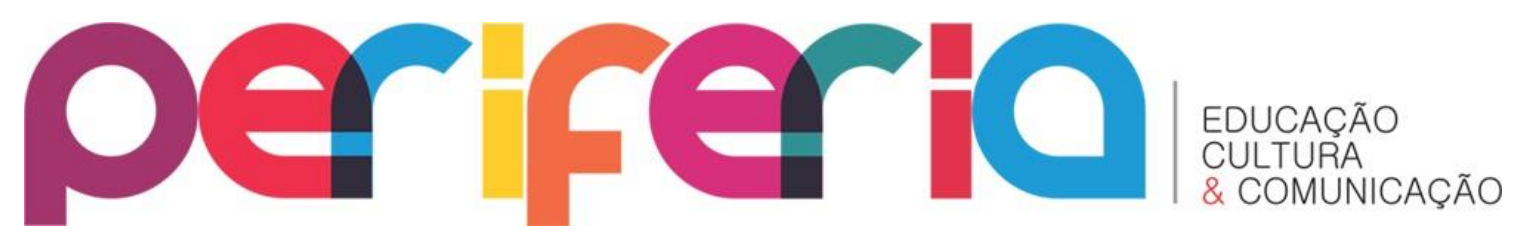

\subsection{SALA LÍNGUA DE INSTRUÇÃO LIBRAS E A FORMAÇÃO DO PEDAGOGO}

A sala Língua de Instrução Libras ${ }^{4}$ se torna indispensável como espaço facilitador para a aquisição de linguagem da criança surda. Sabe-se que a maior parte dos surdos são filhos de pais ouvintes, o que dificulta o processo de aquisição de linguagem no espaço familiar (LACERDA; SANTOS; MARTINS, 2016). A escola passa a ter uma responsabilidade com a aquisição de linguagem e com o conhecimento. Essas salas mencionadas se diferem de outras, pois foge ao padrão, cuja língua majoritária é o português. No caso das salas com instrução em Libras, existe toda uma ideologia, apoiada e aprovada pelo Decreto 5.626/05 (BRASIL, 2005), concedendo o direito de ensino às pessoas surdas pela Libras. Essa proposta educacional promove para a criança ou jovem, além da aquisição de linguagem a oportunidade de inserção na sociedade por meio de trocas e reconhecimento com/de pares surdos, e ainda, experiências, diálogos, concepções e a participação desse grupo sociocultural em todas as esferas de atividade humana em equidade com os ouvintes. As salas de instrução Libras são uma forma de construir o conhecimento de mundo e conhecimento escolar por meio de uma língua que não tenha impedimento orgânico para o sujeito surdo. Tal proposta ainda viabiliza as crianças surdas estarem em contato com crianças ouvintes no ambiente escolar, mas ampara o contato surdo-surdo prioritário para a aquisição de linguagem. A mediação não é feita por meio de intérpretes, já que o processo tradutório não é adequado para crianças em processo de aquisição de linguagem.

O decreto federal, ao abrir a possibilidade para a proposição de outros espaços para se organizar a educação de surdos que

\footnotetext{
${ }^{4}$ Usaremos variadas nomenclaturas: sala de instrução em Libras, sala Língua de instrução Libras ou ainda, sala Libras como língua de instrução, no entanto, se referem ao mesmo movimento. Salas de uso da língua de sinais como língua de relações pedagógicas. As várias nomenclaturas aparecem em pesquisas.
} 


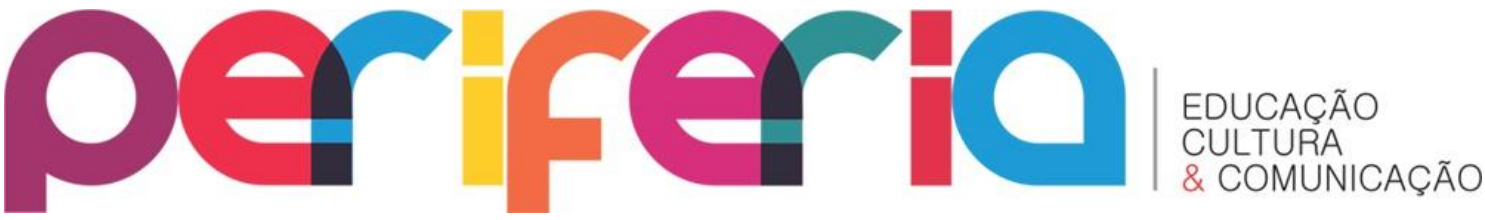

não apenas as salas regulares de ensino desde que respeitados os princípios da educação bilíngue, amplia o conceito de inclusão escolar para o de inclusão social e, ao garantir aos surdos o direito à educação em Libras, possibilita a participação deste grupo sociocultural em todas as esferas de atividade humana em equidade aos ouvintes. (LODI; ALBUQUERQUE, 2016, p. 48)

A sala de instrução Libras deve ter um professor bilíngue, ou seja, o profissional graduado em Pedagogia, com curso de pós-graduação ou com formação superior e certificado de proficiência em Libras, promovido pelo Ministério da Educação (BRASIL, 2005), além disso, com conhecimento e fluência na Libras e na língua portuguesa. São salas no turno que a criança estuda, tendo como foco o ensino do conteúdo escolar pela Libras. Diferente das propostas inclusivas gerais, a criança não aprenderá Libras no contraturno, no atendimento educacional especializado (AEE). Nessa perspectiva o aluno surdo terá aula em Libras o tempo todo que está na escola, no turno escolar. As mesmas englobam as etapas de ensino da Educação Infantil e também do Ensino Fundamental, especificamente nos ciclos I e II.

As salas bilíngues com instrução em Libras são reforçadas no documento legal:

$1^{\circ}$ São denominadas escolas ou classes de educação bilíngue aquelas em que a Libras e a modalidade escrita da Língua Portuguesa sejam línguas de instrução utilizadas no desenvolvimento de todo o processo educativo.

$2^{\circ}$ Os alunos têm o direito à escolarização em um turno diferenciado ao do atendimento educacional especializado para o desenvolvimento de complementação curricular, com utilização de equipamentos e tecnologias de informação. (BRASIL, 2005, p. 5)

Embora haja muita divergência sobre a construção de salas específicas para alunos surdos, ou melhor, salas em que a língua de relações seja a Libras, há várias defesas de que seja necessária essa separação, justamente por se tratar de universos linguísticos e necessidades distintas. O contra- 


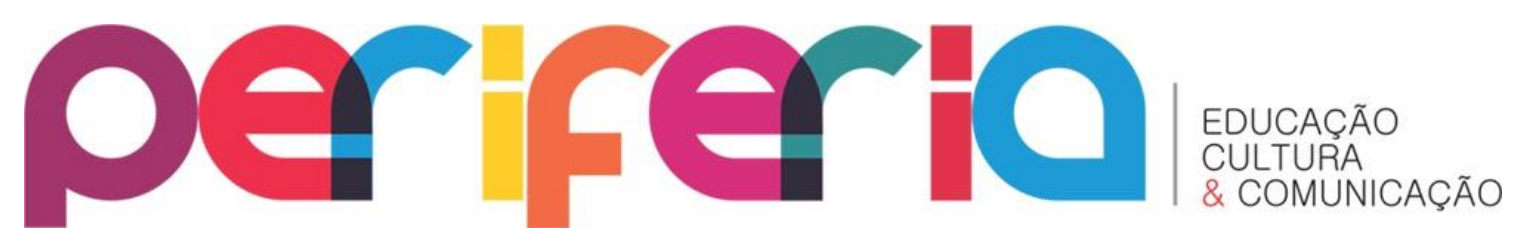

argumento a essa proposta é a defesa atual da existência de salas de aulas inclusivas, surdos e ouvintes, isso pela Política Nacional de Educação Especial (PNEE) (BRASIL, 2008), apoiados pelo intérprete educacional (LODI, 2013). No entanto, se o aluno surdo não sabe Libras a interação fica comprometida, e, assim, não necessariamente há conquista de um espaço favorável para o desenvolvimento de linguagem; uma vez que os alunos ouvintes também não tem língua o suficiente para interagir com os alunos surdos.

Quando a perspectiva inclusiva, ditada pela PNEE, coloca o interprete nos anos iniciais, induz-se a concepção da Libras como um código, sendo dessa maneira o ensino primordial para os ouvintes e não para os surdos. Além de ser um descompasso, conforme apontado, colocar o intérprete para atuar com alunos em fase de aquisição de linguagem. Na perspectiva inclusiva, o interprete pode substituir o professor bilíngue, no entanto, o que está em pauta, não é o processo de aquisição da língua de sinais desses sujeitos, como prioridade no desenvolvimento da criança, e sim o "estar junto socialmente", mesmo que a isso custe à própria lógica inclusiva.

Assim, Lodi (2013) e Lodi e Abuquerque (2016) afirmam que a educação de surdos no nosso país pode ser observada de duas maneiras bastante divergentes. De um lado, a que é prevista pela Declaração de Salamanca e pelo Decreto 5.626/05, documentos que, ao reconhecerem o direito e a diferença linguístico-cultural dos surdos, dispõem sobre uma educação pensada para esta minoria, em Libras. De outro lado, aquela defendida pela Política Nacional de Educação Especial (PNEE), atribui, de forma velada, um caráter instrumental a Libras, ao construir um discurso que aceita a entrada desta língua no interior da escola por meio da presença de tradutores e intérpretes de Libras em todos os níveis e etapas educacionais, sem questionar a importância desta língua e de uma educação realmente construída a partir dela para os estudantes surdos. Observa-se, portanto, o discurso da deficiência e não da diferença, já que em variadas práticas escolares presentifica-se um discurso patológico que busca reparar o surdo de sua deficiência por meio do acesso à língua oral. A Libras não é uma língua de 


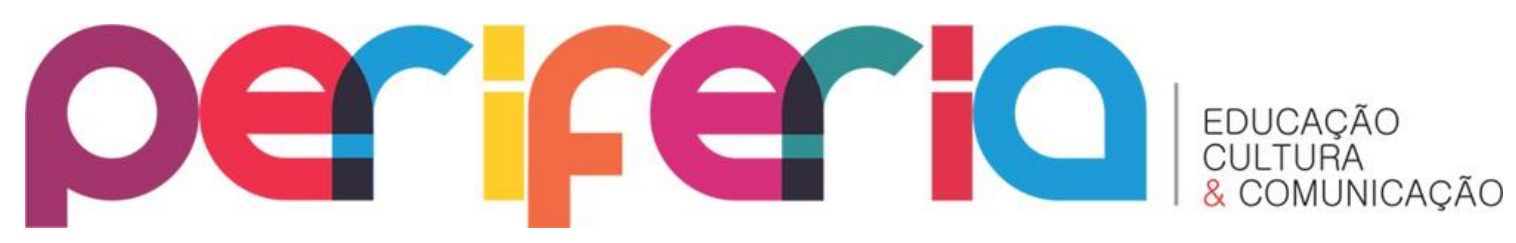

prestígio e sendo os surdos uma minoria linguística, há que se manter a resistência sempre viva aos modelos opressivos (MARTINS, 2008a).

Tratando-se da importância da formação do profissional para uma educação bilíngue, o pedagogo bilíngue se torna indispensável e primordial, na proposta almejada em que as salas se configurem como bilíngues (Libras/Português), nos anos iniciais. 0 professor bilíngue deve pensar em metodologias pedagógicas para a aquisição da Libras e os conteúdos curriculares, tendo em mente as especificidades desse grupo. Todavia, qual é essa formação? Onde encontramos cursos que formam pedagogos bilíngues conforme proposta legal?

Art. $5^{\circ} \mathrm{A}$ formação de docentes para o ensino de Libras na Educação Infantil e nos anos iniciais do Ensino Fundamental deve ser realizada em curso de Pedagogia ou curso normal superior, em que Libras e Língua Portuguesa escrita tenham constituído línguas de instrução, viabilizando a formação bilíngue. (BRASIL, 2005, p. 1)

Nota-se que a não priorização da formação do pedagogo para atender essa demanda surda revela desvalorização efetiva de um modelo bilíngue. E diante do exposto conclui-se que a visão da língua oral como premissa, ou ainda, o mito do monolinguísmo no Brasil, pela língua portuguesa ainda é forte e real, sufocando dessa forma a língua de sinais, e outras línguas minoritárias no âmbito educacional - já que modelos bilíngues em escolas comuns têm sido promovidos por meio de projetos e não como políticas públicas. Há que se voltar na questão de como está sendo a formação desse profissional pedagogo que deveria atuar nessa esfera bilíngue, nas escolas comuns: como deveria ser feita e se está em funcionamento a proposta do decreto 5.626/05. Veremos a imposição da disciplina de Libras na formação do pedagogo, mas: ela em si dá conta? Falaremos desse e outros pontos que desdobram essa temática. 


\section{periferio}

\section{PERCURSOS METOdOLÓGICOS PARA PESQUISA}

Este estudo caracterizou-se como uma pesquisa de abordagem qualitativa descritiva com análise documental, que segundo Trivinos (1987) deve ser entendida como uma atividade de investigação cuidadosa e refletida, embasando-se nos documentos como balizas históricas produtoras de saberes.

Em relação aos passos da pesquisa, realizamos um estudo bibliográfico sobre a educação de surdos, um adensamento reflexivo nesse objeto, e a análise documental na perspectiva de uma análise qualitativa. Foram selecionadas algumas obras entre livros e artigos científicos a partir de buscas por palavras-chaves, sendo essas: surdez, pedagogia bilíngue, inclusão escolar. Tais obras serviram como fundamentação teórica para a pesquisa.

Ao recolher os materiais para a leitura, foi feita ainda uma tabela para melhor seleciona-los. Nesta tabela de dados foram consideradas as seguintes informações: o título da pesquisa; o autor; o ano de publicação e categorias determinadas pela pesquisadora para melhor organiza-las, sendo essas: política, educação e surdez.

Para a seleção das pesquisas acadêmicas levantadas, considerou ainda o objetivo desse estudo e a aproximação com o material encontrado. Sendo assim foram selecionados primeiramente nove artigos e além destes dois documentos específicos para que a análise documental fosse efetuada: A Política Nacional de Educação Especial na Perspectiva da Educação Inclusiva (BRASIL, 2008) e o Decreto 5.626/05 (BRASIL, 2005) para chegar ao entendimento da dinâmica da política inclusiva em contraponto com a política de educação bilíngue - que pode promover uma ressignificação ao que se pensa sobre inclusão.

Para fechamento da análise buscou-se pensar a formação do pedagogo a partir de pesquisas realizadas nas grades e ementas online nos sites das Universidades Federais do Estado de São Paulo, relacionando se a carga horária, o número de créditos oferecidos, proposto na disciplina, é suficiente 


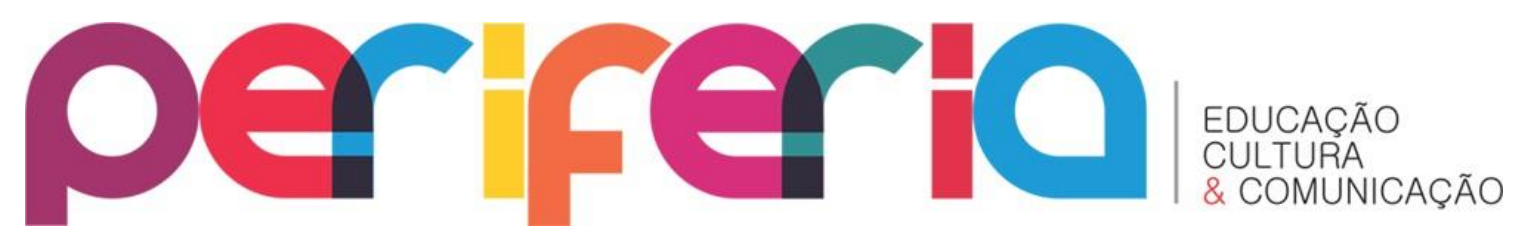

para formar pedagogos bilíngues a partir do que se prevê o Decreto 5.626/05. Por questões de tempo de pesquisa não estendemos as análises para Universidades Estaduais, nem particulares que formam pedagogos. Para esse trabalho traremos as análises contidas apenas nos dados coletados em uma das universidades, aqui nomeada como $\mathrm{U} 1$, porque a partir destes dados derivam-se as demais considerações.

Os dados coletados foram analisados a luz das referências teóricas escolhidas bem como pela perspectiva apontada nos dois documentos legais analisados. A reflexão objetivou a verificação se há de fato uma proposta bilíngue de ensino de surdos sendo implantada por meio da formação pedagógica no Estado de São Paulo e qual a perspectiva ideológica que tem sido assumida hoje nas práticas escolares.

\section{DESAFIOS DA EDUCAÇÃO BILÍNGUE NARRADOS A PARTIR DA FORMAÇÃO DO PEDAGOGO: ANÁLISE DE UMA MATRIZ CURRICULAR}

Após a discussão teórica empreendida, neste momento, por questão de escolha, apresentaremos dados de uma das ementas proposta nas grades curriculares analisadas dos cursos de Licenciatura em Pedagogia. 0 recorte de análise foi de Universidades Federais do Estado de São Paulo. Na busca foram encontradas três universidades com curso de pedagogia às quais seguimos nossa observação. Nomeamos aqui por: U1, U2 e U35. As análises, portanto, serão apenas da primeira Universidade mencionada: U1, já que nos demais cursos observados a lógica de estruturação, com algumas distinções, foram praticamente a mesma.

\footnotetext{
5 Ressalta-se novamente que no trabalho de conclusão de curso foram analisadas três universidades. No entanto, para esse artigo recortamos apenas as análises realizadas na proposta curricular de uma universidade, U1. Optamos pelo uso de sigla para representar a Universidade analisada para não criar nenhum tipo de constrangimento, já que a identidade do local não importa para as análises. Para os interessados, indicamos a leitura do trabalho na integra.
} 


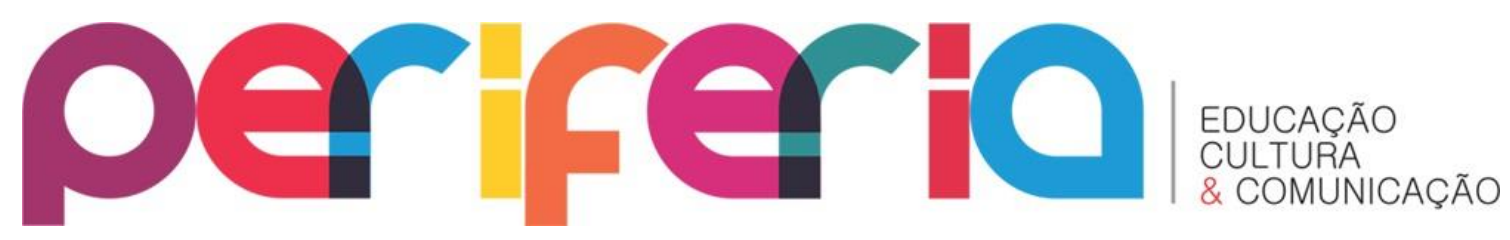

0 Decreto 5.626/05 como mencionado anteriormente afirma a responsabilidade de abertura de salas bilíngues, o que pressupõe para isso a formação docente de educadores bilíngues. Além do garantido, em relação à educação bilíngue apresenta-se a proposta sobre a formação esperada para os profissionais que atuarão com sujeitos surdos no espaço escolar. Para isso, pressupõe cursos de pedagogia bilíngue, de um lado, e, contrariamente, aponta a criação da disciplina de Libras na pedagogia e nos cursos de licenciaturas, como suporte inicial de contato sobre a surdez e os aspectos linguísticos da Libras pelo estudante.

É notável que a proposta de inserção da Libras como disciplina curricular torna-se importante na medida em que apresenta aos futuros profissionais a questões da surdez e da língua de sinais, diminuindo algumas representações errôneas sobre questões culturais e identitárias dos surdos. Porém ao disseminar a disciplina de Libras nos cursos de formação de pedagogos, não foi priorizada, no Estado de São Paulo, a consolidação e abertura de cursos específicos de pedagogia bilíngue, também expresso e orientado no documento. Sobre aspectos da formação de profissionais que atuarão com as pessoas surdas, vê-se:

Art. $5^{\circ}$ A formação de docentes para o ensino de Libras na educação infantil e nos anos iniciais do ensino fundamental deve ser realizada em curso de Pedagogia, ou curso normal superior, em que a Libras e Língua Portuguesa Escrita tenham constituído línguas de instrução, viabilizando a formação bilíngue. (BRASIL, 2005, p. 1)

Um adendo a ser destacado é que o documento aponta a formação de pedagogia para o ensino de Libras, mas, o curso de pedagogia tem como função formar professores para ensino nos anos iniciais de todas as disciplinas. Entende-se que a intenção do documento é pensar a formação de docentes nos anos iniciais, para além do ensino da língua de sinais, no entanto, ao apontar o ensino da língua de sinais como primazia na formação desse profissional, deixa as demais funções do pedagogo bilíngue descoberta. 


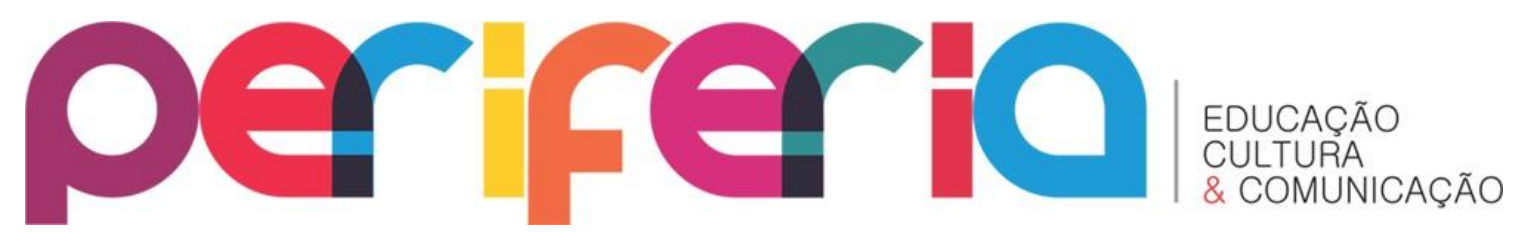

Evidente que a língua é foco no ensino, contudo os demais conteúdos deverão ser ensinados por meio dessa língua - isso não fica claro na lei e pode ser motivo de desajustes em práticas escolares e formativas.

Diante do estudo (LODI, 2013) nota-se que a atuação do pedagogo é comprometida, primeiramente por não se ter a formação especializada como o Decreto 5.626/05 (BRASIL, 2005) propõe, e depois por atender a política inclusiva e não linguística. Na prática se coloca o intérprete como o profissional responsável para a aquisição de linguagem do aluno surdo nos anos iniciais. No entanto, sabemos que a formação de intérprete não prioriza práticas de ensino de surdos para os anos iniciais, como alfabetização e letramento. Até porque não seria esse profissional o responsável por esses afazeres, embora na realidade, a instrução fica a mercê do intérprete, quando a inclusão se faz por meio de sua presença. Temos aqui um descompasso na proposta da educação bilíngue, no momento em que o Decreto 5.626/05 aponta a obrigatoriedade do profissional bilíngue em sala de aula da Educação Infantil e dos anos iniciais do Ensino Fundamental, e na prática isso não acontece (MARTINS, 2008a).

Sobre a análise dos planos de ensino do curso de Licenciatura em Pedagogia na Universidade U1, pode-se ver uma carga horária de 75h, para a disciplina ofertada com enfoque na área da surdez. A mesma é dividida em 35,5h teóricas e $35,5 \mathrm{~h}$ práticas, ficando exclusas $4 \mathrm{~h}$ dessa programação, sem definição aparente. Como trouxemos dados dessa universidade vale ressaltar que umas das diferenças encontradas das outras duas e que chamou atenção foi exatamente a carga-horária ampliada de 30 horas para 75. Uma diferença importante, no entanto, tal expansão no tempo objetivava a caracterização de aspectos da prática inclusiva, conforme descrição da ementa que será apresentada e não foco específico para o ensino bilíngue. Não encontramos um adensamento nas questões de ensino de surdos voltadas à necessidade de formação do pedagogo - dado comum nos demais cursos analisados.

Observa-se que a parte prática de ensino da língua é pequena, se pensarmos na atuação de um futuro educador que deverá lidar com alunos 


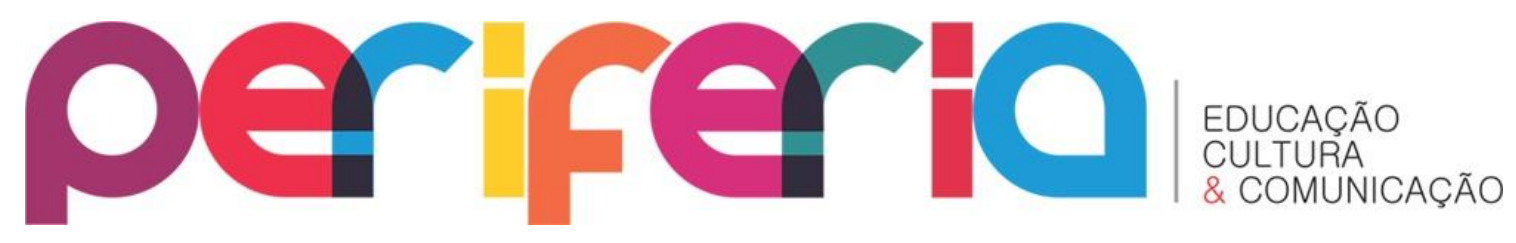

surdos em processo de alfabetização. Além disso, mesmo com a ampliação de horas para a disciplina, com esse tempo de aula, e pouca inserção de uma mudança curricular focada para especificidades de alunos surdos, é difícil adensar aspectos teóricos como questões culturais, didática de ensino para surdos, pedagogia visual, aquisição de linguagem, identidade e surdez, entre outros aspectos relevantes.

Quadro 1: Grade curricular do curso de Licenciatura em Pedagogia - U1.

\begin{tabular}{|l|l|l|l|l|l|}
$7^{\circ}$ & Educação Bilingue: Libras/ Língua Portuguesa (F/DC) & 75 & 7 & 35,5 & 35,5 \\
\hline
\end{tabular}

Fonte: Projeto Político Pedagógico do curso

Analisando primeiramente a carga horária prevista na ementa, pode-se perceber uma alteração no que se diz respeito às horas destinadas para a prática e para teoria. Na grade curricular, têm-se às $75 \mathrm{~h}$ divididas conformo apontado acima, já na ementa, diz-se que $70 \%$ das horas são destinadas à prática e $30 \%$ à teoria. Uma questão posta: se a lógica da formação em pedagogia é formar um professor generalista, como ficam as especificidades linguísticas de sujeitos que não tem o português como primeira língua? E mais, se a disciplina de Libras, mesmo que com nomes distintos, pretende dar um "suporte" para o pedagogo, quem de fato será o educador desse aluno? Tais questões nos direcionam para a lógica inclusiva, e um ensino voltado para um grupo majoritário, as especificidades linguísticas ficam para o turno contrário de estudo, em espaço de atendimento especializado.

0 departamento que assegura o desenvolvimento da disciplina nesta Universidade é o de Pedagogia. Outro ponto interessante é que a disciplina é nomeada: Educação Bilíngue: Libras/ Língua Portuguesa, mas ao observar o conteúdo pragmático, que é a única parte que se fala da Educação Bilíngue, a mesma está posta apenas como introdutória. Não há um adensamento para a efetivação da construção de uma proposta de educação bilíngue em situações de inclusão, em espaços não favoráveis para isso. Não há aspectos voltados à alfabetização e letramento de surdos. Considera- se a falta de horas 


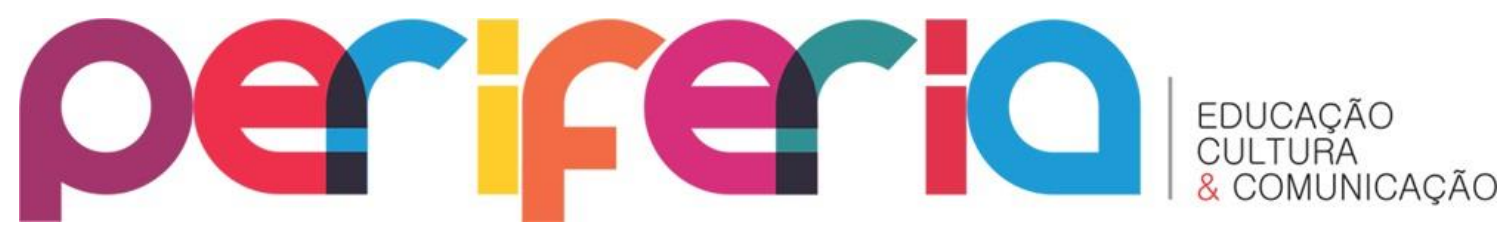

destinadas à formação plena do pedagogo bilíngue proposta no Decreto 5.626/05 (BRASIL, 2005).

No que se diz respeito aos objetivos da ementa da disciplina se apresentam:

Quadro 2: Objetivo da disciplina de Educação Bilíngue: Libras/ Língua Portuguesa do Projeto Político Pedagógico

\section{OBJetivos}

- Conhecer as políticas educacionais que tratam dos direitos linguísticos e inclusão social do surdo e refletir sobre o contexto educacional e a efetividade dessas políticas a partir das vivências na Residência Pedagógica ou outras experiências escolares.

- Conhecer a educação do surdo no contexto da Educação Especial Brasileira: história, fundamentos e perspectivas.

- Vivenciar a LIBRAS para construir aproximações quanto a questões metodológicas do ensino e aprendizagem de LIBRAS

- Desenvolver sensibilidade e compreender o papel do professor na inclusão escolar de alunos surdos

- Desenvolver sensibilidade e compreender o papel do gestor escolar na inclusão de alunos surdos na escola

Fonte: Projeto Político Pedagógico, 2009

Todos os tópicos apresentados são de extrema relevância. 0 fato é que a disciplina embora receba o nome de "Educação Bilíngue" visa preencher a obrigatoriedade posta da disciplina de Libras para alunos da licenciatura. A proposta da disciplina tem um lugar social importante, no entanto, apenas ela não formará educadores aptos para as salas língua de instrução Libras - já apresentadas em tópico anterior nesse texto. Parece que não há interesse político para esse fim. De modo geral, a disciplina oferece um processo inicial, de desmistificação da surdez e conhecimento raso sobre a língua de sinais - como todas as demais universidades observadas. Evidente que em si já é um ganho para as comunidades surdas, porém, essa mesma proposta auxilia para a continuidade de uma política educacional promovida pela instrumentalização da língua de sinais. Nota-se que na ementa da disciplina encontramos temas relacionados à educação bilíngue e ao conhecimento das políticas educacionais, em relação aos direitos linguísticos. O contexto educacional e a efetividade dessas políticas se tornam essenciais por todo o 


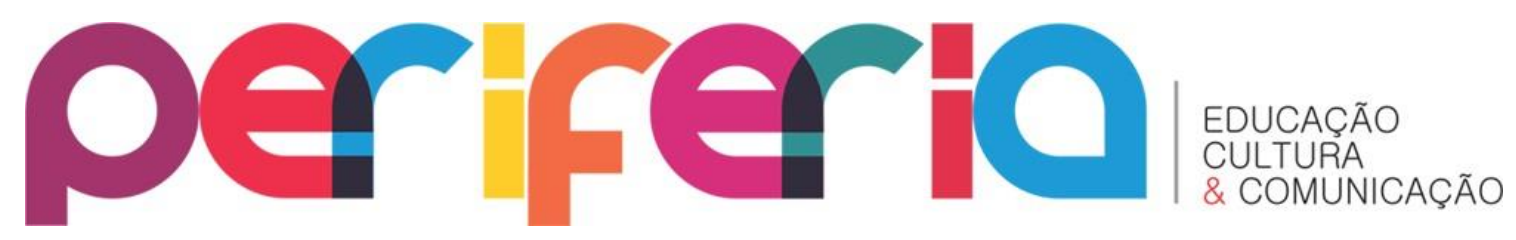

percurso descrito neste trabalho. Reforçamos que o professor bilíngue deverá ter conhecimento dos mesmos, mas deve-se pensar sobre o tempo para tais discussões em sua formação. Diante disso, aprofundar aspectos sobre a história de surdos, fundamentos e perspectivas de uma educação bilíngue nos anos iniciais, metodologia de ensino, entre outras habilidades necessárias em 75h de curso nos parece insuficientes. O aluno não conquistará fluência na Libras nesse curto espaço de formação. Ao que parece, pelos objetivos, a proposta é de introduzir a aprendizagem da Libras.

Segundo Martins (2008b), há vantagens e desvantagens da disciplina de Libras nas licenciaturas. Vantagens em relação ao contato com a língua de sinais e aspectos da surdez e desvantagens em relação ao "tiro no pé" sobre a perspectiva bilíngue, uma vez que apoiados pela lei, o mínimo ofertado aos educadores os considera formados para atender à demanda educacional de educandos surdos.

Processo perverso que potencializa a doce ilusão no sujeito do reconhecimento de sua língua e cultura, - tomado pelo autor como ilusão da minoria - ilusão de estar avançando em sua luta, quando na verdade suas petições estão tornando-se folclorizadas no cotidiano da sociedade. A identidade cultural da minoria, nessa lógica, fica comprometida, apagando-se; o sujeito da minoria passa a não se reconhecer mais dentro do grupo e busca na mesmidade da maioria fazer-se corpo (MARTINS, 2008b, p. 200).

Retomando as questões práticas do ensino de Libras no currículo analisado, apesar do objetivo de vivenciar a Libras, quando se compara com outras línguas orais, o investimento de aprendizagem e tempo destinado para isso é muito maior. Como então aprender uma segunda língua, depois de adultos, para ser modelo linguístico de crianças surdas, participando ativamente de sua alfabetização, com somente $75 \mathrm{~h}$ ? Se entendermos que a Libras é uma língua com todos os quesitos de uma língua oral, tal proposta parece insuficiente e muita audaciosa. Ou, na pior das hipóteses reflete a 


\title{
periferio
}

falta de reconhecimento linguístico devido e a manutenção da língua portuguesa como único meio de formação para os surdos na escola comum.

\section{Quadro 3: Ementa da disciplina de Educação Bilíngue: Libras/ Língua Portuguesa do Projeto Político}

\begin{abstract}
EMENTA
Os marcos históricos da educação dos surdos e a história dos movimentos políticos organizados por associações de surdos e suas conquistas; as especificidades do sujeito surdo e sua respectiva identidade, a diferença entre linguagens e língua - implicações para se pensar os processos identitários; a Língua Brasileira de Sinais (LIBRAS) em suas singularidades lingüísticas e seus efeitos sobre o desenvolvimento, aquisição da lingua(gem) e produções culturais; questões metodológicas do ensino e aprendizagem de LIBRAS; bases epistemológicas para se entender a inclusão de pessoas surdas.
\end{abstract}

Fonte: Projeto Político Pedagógico, 2009

A partir da ementa prevista no Projeto Político Pedagógico, pode-se ver que não existe um momento que se discuta e debata as questões de uma pedagogia bilíngue, que seria a parte fundamental da formação desse profissional. 0 mais aproximado que se chega são as questões metodológicas do ensino e aprendizagem da Libras, mas não se especifica ou se adensa na formação bilíngue. 0 foco parece voltar-se ao ensino da Libras. 0 que fica evidente é uma perspectiva que invisibiliza a Libras na escola, na medida que não promovem cursos de formação específicos para professores bilíngues e pensa a formação do pedagogo apenas com conhecimentos superficiais e introdutórios da língua de sinais e de aspectos da educação do surdo. Tais bases revelam a proposta que se pretende manter: a lógica inclusiva, com um professor que é sensivel ao surdo, mas que não promoverá ensino/instrução pela língua de sinais. Martins (2008b) ressalta que há que se fazer "investimento no campo dos direitos políticos, buscando mudanças representativas na escola para a conquista do tão almejado ensino bilíngue" (p. 202) por meio da formação docente, e de embates constantes. A disciplina de Libras introduzida no currículo da pedagogia sensibiliza o educador, mas por outro lado não potencializa o investimento na consolidação de cursos de 


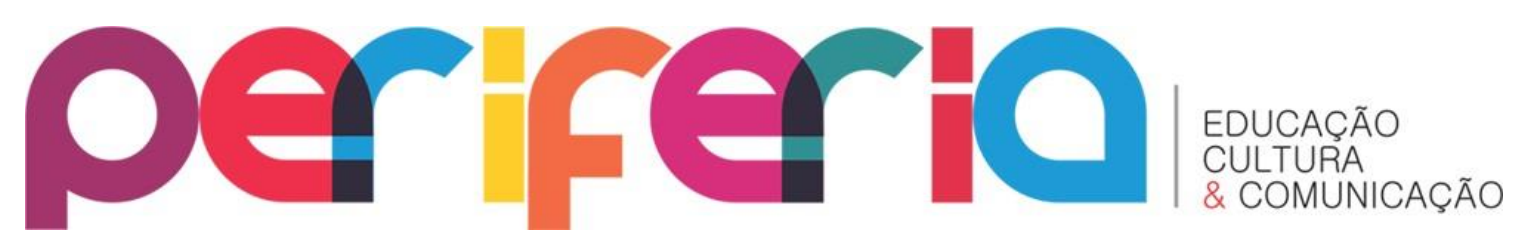

pedagogia voltados ao campo da surdez, numa vertente cultural, com base na Libras como constituidora de práticas docentes.

\section{CONSIDERAÇÕES FINAIS}

No decorrer deste trabalho percebe-se a importância da educação bilíngue de surdos, ou seja, Libras como primeira língua e a Língua Portuguesa como segunda, em sua modalidade escrita. O Decreto 5.626/05 se coloca como um documento norteador e de extrema importância para a argumentação e implantação de propostas bilíngues nas escolas das redes regulares de ensino. Além disso, nota-se a relevância das salas língua de instrução Libras para alunos surdos nos anos iniciais. A abertura destas salas justifica-se pela metodologia de ensino diferenciada, tendo a Libras como articuladora de todo processo educacional. Outra questão essencial que merece destaque é a importância da aquisição de linguagem na Educação Infantil e nos anos iniciais do Ensino Fundamental por crianças surdas, principalmente as filhas de pais ouvintes. Tal proposta só se efetiva com a presença de profissionais especializados para esse atendimento. Apostamos no pedagogo bilíngue (se possível surdos) como profissional fundamental para esse processo, nos anos iniciais. Como suporte para a promoção de uma escola outra, apresentou-se a propostalprojeto de Escolas-Polo, desenvolvidas em alguns municípios do estado de São Paulo, e o sucesso obtido no desenvolvimento do aluno surdo no que se refere a sua aprendizagem e questões identitário-culturais.

O contexto histórico, tanto das lutas das comunidades surdas, como dos documentos legais aqui apresentados, sendo eles o Decreto 5.626/05 e a Política Nacional de Educação Especial na Perspectiva da Educação Inclusiva (PNEE) se colocam como agenciadores de políticas escolares. A proposta de ensino de muitas escolas reflete mais o que prevê na política de educação especial que no Decreto 5.626/05, pois promove um ensino de surdos mediado por profissionais que desconhecem a língua de sinais, baseada pela lógica do 


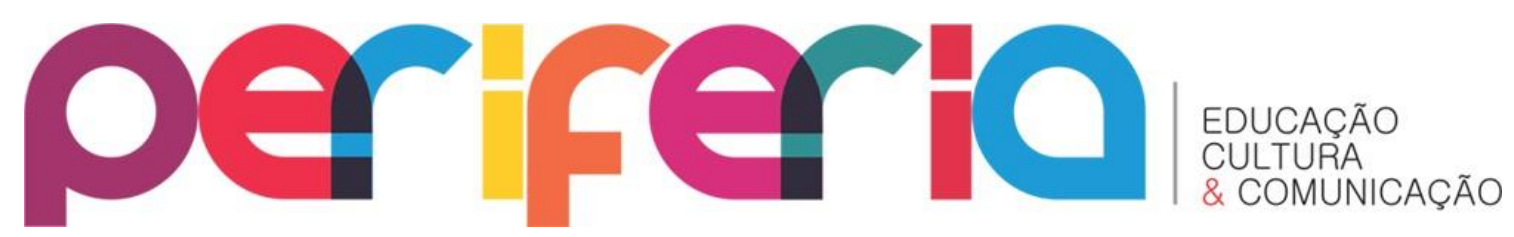

atendimento especializado, no contraturno. Esse modo de fazer educação não se faz suficiente para atender as especificidades dos surdos, e ainda, mantém-se a lógica da surdez como deficiência e não como diferença linguística. Essa perspectiva, ainda, se põe contra as salas língua de instrução Libras, um dos componentes cruciais para o aprendizado das crianças surdas, conforme analisado em obras e artigos levantados por essa pesquisa.

No que se trata da educação bilíngue, retomando ao ponto principal deste artigo, refletiu-se sobre a formação do pedagogo, o qual irá atender alunos surdos nos anos iniciais. A questão norteadora foi se a formação atual contempla a proposta desenhada pelo Decreto 5.626/05. Diante disso, perguntou-se se a formação bilíngue está sendo de fato atendida e, pela análise curricular compreende-se que a perspectiva ideológica mantida é de um conhecimento básico das questões da surdez pelo educador, não qualificando uma política bilíngue.

Assim, essa pesquisa trouxe como contribuição a observação de que nas Universidades Federais do Estado de São Paulo Estado a formação da pedagogia voltada à proposta bilíngue para surdos tem sido insuficiente, ou melhor, não há uma formação específica para esse fim; apenas a oferta de disciplinas de Libras com carga-horária entre 30 a 75 horas, ainda que apresentadas com nomes distintos. Ou seja, não confere com o proposto no Decreto 5.626/05 - formação bilíngue. Dessa maneira, encontra-se nas escolas atuais um descompasso na educação, no que se refere ao modelo de ensino bilíngue, já que o ensino de surdos é feito por pedagogos sem formação adequada para a sua realização. Não há como oferecer escolas bilíngues se a formação ofertada não se alinha a essa perspectiva. A visão da oralidade como premissa para a formação humana mantém-se presente. Além do pedagogo, (nos anos específicos descritos acima), não ter o conhecimento devido da língua, os alunos surdos são destinados a outros profissionais como o tradutor e interprete (que deveria atender somente a partir do $6^{\circ}$ ano, conforme legislação), ou para o próprio educador especial que atende no contraturno em períodos curtos - desse modo o turno fica prejudicado. 


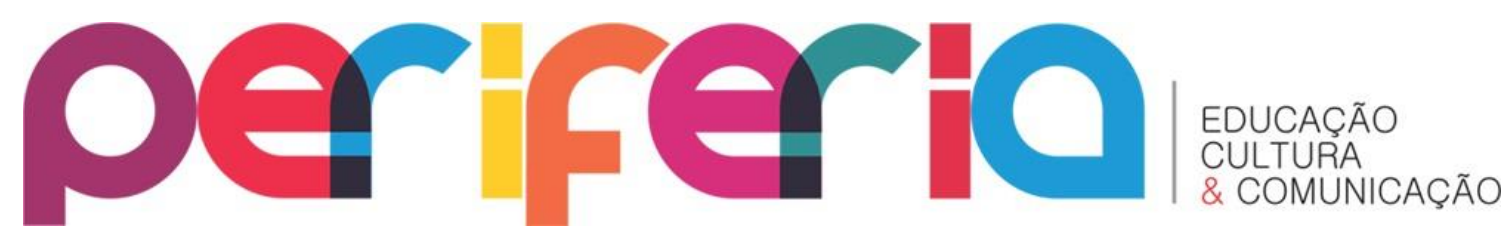

Consideramos que essa pesquisa abre caminhos para se entender como a política de formação produz (novas/velhas) práticas escolares, e ainda, como a ideologia inclusiva dirige a formação de professores, pervertendo o Decreto 5,626/05 (BRASIL), ou ainda, produzindo matrizes distintas políticas pautadas na perspectiva inclusiva. E como análise final observa-se que a disciplina de Libras, em muitos espaços, tem sido promovida como instrumento de "inclusão". Essa reflexão foi realizada em uma amostra pequena, nas universidades federais do Estado de São Paulo, apontando um recorte de análise de uma das universidades que oferece o curso de pedagogia, mas pode ser expandida para outras realidades.

\section{REFERÊNCIAS}

BRASIL. Política de educação especial na perspectiva da educação inclusiva. Documento elaborado pelo Grupo de Trabalho nomeado pela Portaria Ministerial $n^{\circ} 555$, de 5 de junho de 2007, prorrogada pela Portaria $n^{\circ} 948$, de 09 de outubro de 2008. Brasília: MEC, 2008. Disponível em: http://portal.mec.gov.br/arquivos/pdf/politicaeducespecial.pdf Acesso em: $12 / 03 / 2017$

BRASIL. Decreto $n^{\circ} 5.626$, de 22 de dezembro de 2005. Regulamenta a Lei $n^{\circ}$ 10.436, de 24 de abril de 2002, que dispõe sobre a Língua Brasileira de Sinais (LIBRAS). Disponível em: < http://www.planalto.gov.br/ccivil_03/_ato20042006/2005/decreto/d5626.htm>. Acesso em: 01 mai. 2016.

GESSER, Audrei. Libras? Que língua é essa? Crenças e preconceitos em torno da língua de sinais e da realidade surda. São Paulo: Parábola Editorial, 2009. $83 \mathrm{p}$.

LACERDA, Cristina Broglia Feitosa de; SANTOS, Lara Ferreira dos; MARTINS, Vanessa Regina de Oliveira. Escola e Diferença: caminhos para educação bilíngue de surdos. São Carlos: EdUFSCar, 2016. 241 p.

LACERDA, Cristina Boglia Feitosa de. Um pouco das diferentes abordagens na educação dos surdos. Caderno Cedes, Campinas, vol.19, n.46, set. 1998.

LACERDA, C.B.F.de; SANTOS, L.F.dos; LODI, A.C.B.; GURGEL, T. Educação inclusiva bilíngue par alunos surdos: pesquisa e ação em uma rede pública de ensino. In: LACERDA, Cristina Broglia Feitosa de; SANTOS, Lara Ferreira dos; 


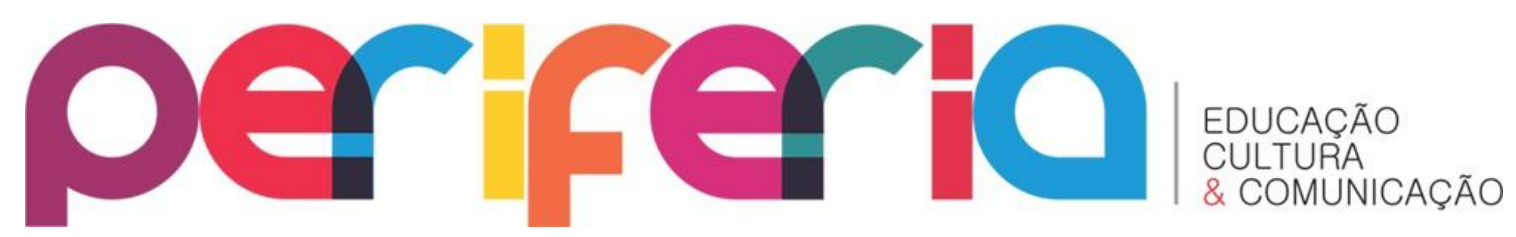

MARTINS, Vanessa Regina de Oliveira (Orgs). Escola e Diferença: caminhos para educação bilíngue de surdos. São Carlos: EdUFSCar, 2016. pp 13-28.

LODI, Ana Claudia Balieiro. Educação inclusiva para surdos e inclusão segundo a política nacional de educação especial e o decreto $n^{\circ} 5626 / 05$. Educação e Pesquisa. São Paulo, v. 39, n. 1, p. 49-63, jan./mar. 2013.

LODI, A.C.B; ALBUQUERQUE, G.K.T.S.de. Sala Libras língua de instrução: Inclusão ou exclusão educacional/social? IN: LACERDA, C.B.F. de; SAŅTOS, L.F dos; MARTINS, V.R.de O (orgs). In: Escola e Diferença: caminhos da educação bilíngue para surdos. São Carlos: Edufscar, 2016

MARTINS, Vanessa Regina de Oliveira. Educação de surdos no paradoxo da inclusão com intérprete de língua de sinais: Relações de poder e (re) criações do sujeito. Dissertação de Mestrado. Faculdade de Educação da Universidade Estadual de Campinas. UNICAMP, Campinas/SP, 2008a.

MARTINS,V.R.O. Análise das vantagens e desvantagens da Libras como disciplina curricular no ensino Superior. Cadernos do CEOM, Chapecó, SC. Ano 21, n.28, p.191-206, junho, 2008b.

SOARES, M.A.L. A Educação do surdo no Brasil. Campinas: Autores Associados; Bragança Paulista: EDUSF, 1999.

TRIVINOS, A. N. S. Introdução à pesquisa em ciências sociais: a pesquisa qualitativa em educação. São Paulo: Ática, 1987. 